Article

\title{
Purine DNA Lesions at Different Oxygen Concentration in DNA Repair-Impaired Human Cells (EUE-siXPA)
}

\author{
Marios G. Krokidis ${ }^{1,2}$, Eleonora Parlanti ${ }^{3}$, Mariarosaria D'Errico ${ }^{3}$, Barbara Pascucci ${ }^{3,4}$, \\ Anna Pino ${ }^{3}$, Alessandro Alimonti ${ }^{3}$, Donatella Pietraforte ${ }^{5}$, Annalisa Masi ${ }^{1}\left(0\right.$, , Carla Ferreri ${ }^{1}(\mathbb{D}$ \\ and Chryssostomos Chatgilialoglu 1,6,*D \\ 1 Istituto per la Sintesi Organica e la Fotoreattività, Consiglio Nazionale delle Ricerche, Via P. Gobetti 101, \\ 40129 Bologna, Italy; m.krokidis@inn.demokritos.gr (M.G.K.); annalisa.masi@isof.cnr.it (A.M.); \\ carla.ferreri@isof.cnr.it (C.F.) \\ 2 Institute of Nanoscience and Nanotechnology, N.C.S.R. “Demokritos", 15310 Agia Paraskevi Attikis, \\ Athens, Greece \\ 3 Department of Environment and Health, Istituto Superiore di Sanità, Viale Regina Elena 299, 00161 Rome, \\ Italy; eleonora.parlanti@iss.it (E.P.); mariarosaria.derrico@iss.it (M.D.); barbara.pascucci@ic.cnr.it (B.P.); \\ anna.pino@iss.it (A.P.); alessandro.alimonti@iss.it (A.A.) \\ 4 Institute of Crystallography, Consiglio Nazionale delle Ricerche, Monterotondo Stazione, 00185 Rome, Italy \\ 5 Core Facilities, Istituto Superiore di Sanità, Viale Regina Elena 299, 00161 Rome, Italy; \\ donatella.pietraforte@iss.it \\ 6 Center for Advanced Technologies, Adam Mickiewicz University, 61-614 Poznań, Poland \\ * Correspondence: chrys@isof.cnr.it; Tel.: +39-051-639-8309
}

Received: 1 October 2019; Accepted: 31 October 2019; Published: 1 November 2019

check for updates

\begin{abstract}
Xeroderma Pigmentosum (XP) is a DNA repair disease characterized by nucleotide excision repair (NER) malfunction, leading to photosensitivity and increased incidence of skin malignancies. The role of XP-A in NER pathways has been well studied while discrepancies associated with ROS levels and the role of radical species between normal and deficient XPA cell lines have been observed. Using liquid chromatography tandem mass spectrometry we have determined the four 5',8-cyclopurines (cPu) lesions (i.e., $5^{\prime} R$-cdG, 5' S-cdG, 5' R-cdA and 5' S-cdA), 8-oxo-dA and 8-oxo-dG in wt (EUE-pBD650) and XPA-deficient (EUE-siXPA) human embryonic epithelial cell lines, under different oxygen tension (hyperoxic $21 \%$, physioxic $5 \%$ and hypoxic $1 \%$ ). The levels of Fe and $\mathrm{Cu}$ were also measured. The main findings of our study were: (i) the total amount of $\mathrm{cPu}(1.82-2.52$ lesions/10 6 nucleotides) is the same order of magnitude as 8-oxo- $\mathrm{Pu}$ (3.10-4.11 lesions $/ 10^{6}$ nucleotides) in both cell types, (ii) the four $\mathrm{cPu}$ levels are similar in hyperoxic and physioxic conditions for both wt and deficient cell lines, whereas 8-oxo-Pu increases in all cases, (iii) both wt and deficient cell lines accumulated high levels of $\mathrm{cPu}$ under hypoxic compared to physioxic conditions, whereas the 8-oxo-Pu levels show an opposite trend, (iv) the diastereoisomeric ratios $5^{\prime} R / 5^{\prime} S$ are independent of oxygen concentration being 0.29 for cdG and 2.69 for cdA for EUE-pBD650 (wt) and 0.32 for cdG and 2.94 for cdA for EUE-siXPA (deficient), (v) in deficient cell lines Fe levels were significantly higher. The data show for the first time the connection of oxygen concentration in cells with different DNA repair ability and the levels of different DNA lesions highlighting the significance of cPu. Membrane lipidomic data at $21 \% \mathrm{O}_{2}$ indicated differences in the fatty acid contents between wild type and deficient cells, envisaging functional effects on membranes associated with the different repair capabilities, to be further investigated.
\end{abstract}

Keywords: XPA; DNA repair; hypoxia; oxidative lesions; hydroxyl radicals; oxygen concentration 


\section{Introduction}

Xeroderma Pigmentosum (XP-complementation group A-G) is a rare autosomal recessive disorder, which presents itself with an increased incidence of sun-induced skin cancer and of internal cancer [1]. Patients of the complementation group XP-A also are prone to neurodegeneration. Neurological defects appear between 2 and 8 years of age, with microcephaly, mild cognitive impairment followed by cerebellar alterations and, later, neuropathy [2]. XP-A is one of the 30 proteins involved in the nucleotide excision repair (NER), a repair pathway responsible for the removal of those lesions that distort the DNA helix. NER operates by two distinct pathways: global genome repair (GGR) that removes lesions from the genome overall and transcription-coupled repair (TCR) that repairs transcriptionally active domains [3]. XP-A plays a central role in both TCR and GGR. In differentiated cells, XP-A is involved in the transcription-domain associated repair (DAR), a DNA repair system that repairs bulky lesions in both transcribed and non-transcribed strands of active genes, whereas NER is quite absent in non-transcribed genes [4]. It is increasingly evident that NER factors are also involved in the repair of oxidatively generated DNA damage [5]. These lesions are prevalently repaired by the base excision repair (BER), involving specific DNA glycosylases in the removal of damaged bases [6]. In a previous study some of us showed that the XPC-HR23B complex acts as a BER cofactor for 8-oxo-7,8-dihydro-2'-deoxyguanosine (8-oxo-dG, Figure 1b) by stimulating the activity of its specific DNA glycosylase OGG1 [7]. Recently, some of us demonstrated that primary fibroblasts derived from XPA patients accumulate 8-oxo-dG in their genome [8], as already shown in primary fibroblasts derived from XPC patients and from Cockayne Syndrome patients (A and B complementation groups) $[7,9]$. These findings suggested a functional overlap between XPA and XPC in the removal of 8-oxo-dG [8].

(a)<smiles></smiles><smiles>CC1(C(=O)O)c2nc3c(N)ncnc3n2C2CC(O)C(O)C1O2</smiles>
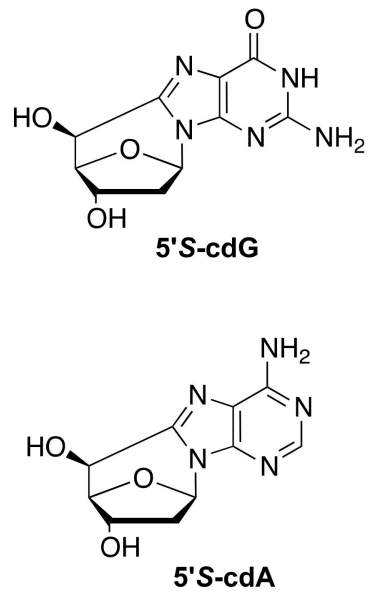

(b)<smiles></smiles><smiles>Nc1ncnc2c1[nH]c(=O)n2C1CC(O)C(O)C1O</smiles>

Figure 1. (a) Structures of $5^{\prime}, 8$-cyclo-2'-deoxyguanosine (cdG) and $5^{\prime}, 8$-cyclo-2'-deoxyadenosine (cdA) in their $5^{\prime} R$ and $5^{\prime} S$ diastereomeric forms. (b) Structure of 8-oxo-2'-deoxyguanosine (8-oxo-dG) and 8-oxo-2'-deoxyadenosine (8-oxo-dA).

Another family of thoroughly investigated oxidative lesions, also for their role in neurodegenerative disease are the purine 5',8-cyclo-2'-deoxynucleosides (cPu). The 5',8-cyclo-2'-deoxyadenosine (cdA) and $5^{\prime}, 8$-cyclo-2'-deoxyguanosine (cdG) exist in $5^{\prime} R$ and $5^{\prime} S$ diastereoisomeric forms (Figure 1a). The peculiarity of these lesions is that they are only repaired by the NER pathway [10-13] with increased efficiency for both $5^{\prime} R$ diastereoisomers compared to $5^{\prime} S$, by a factor of 2 [14-16], whereas they are not removed by BER $[17,18]$. In contrast with other oxidative DNA lesions, $\mathrm{CPu}$ are exclusively generated by hydrogen atom abstraction from the 2-deoxyribose units by $\mathrm{HO}^{\bullet}$ radical. These lesions were found to be: chemically stable [19,20], endogenously formed in mammalian cellular DNA [21-25], 
repaired exclusively by the NER pathway $[14,18,26]$, strongly, but not totally, cause of blockage of the transcription by RNA polymerase II which occurs in cells derived from XP patients [17,27].

It is well known that the concentration of $\mathrm{O}_{2}$ can strongly influence the formation of $\mathrm{cPu}$ [28-31]. Gamma-radiolysis experiments under modulated aerobic conditions were carried out to investigate the formation of $\mathrm{cPu}$ in calf thymus DNA $[30,31]$. It was found that the $\mathrm{C}^{\prime}$ carbon radical is converted quantitatively to $\mathrm{cdA}$ and $\mathrm{cdG}$ in the absence of oxygen, whereas the formation of $\mathrm{cPu}$ decreases in the presence of oxygen, indicating competition paths for $\mathrm{C}^{\prime}$ radical between cyclization and addition to oxygen (Figure 2).

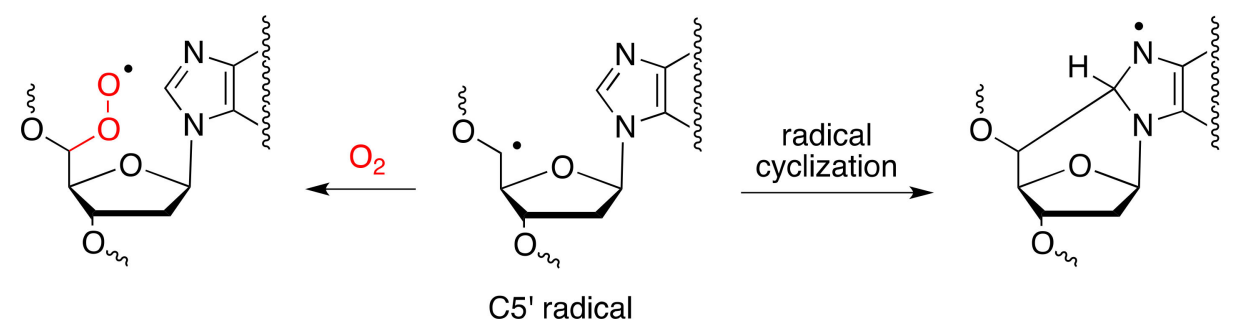

Figure 2. Partition of $\mathrm{C}^{\prime}$ radical between cyclization and addition to molecular oxygen.

The main processes that generate endogenously $\mathrm{HO}^{\bullet}$ radicals are depicted in reactions (1)-(3): the Fenton reaction of $\mathrm{H}_{2} \mathrm{O}_{2}$, the reduction of $\mathrm{HOCl}$ by the superoxide radical anion, and the spontaneous decomposition of protonated $\mathrm{ONOO}^{-}$, respectively [32-34].

$$
\begin{gathered}
\mathrm{H}_{2} \mathrm{O}_{2}+\mathrm{Fe}^{2+} \rightarrow \mathrm{Fe}^{3+}+\mathrm{HO}^{-}+\mathrm{HO}^{\bullet}(1) \\
\mathrm{HOCl}+\mathrm{O}_{2}^{\bullet-} \rightarrow \mathrm{O}_{2}+\mathrm{Cl}^{-}+\mathrm{HO}^{\bullet}(2) \\
\mathrm{ONOO}^{-}+\mathrm{H}^{+} \leftrightarrows \mathrm{ONOOH} \rightarrow{ }^{\bullet} \mathrm{NO}_{2}+\mathrm{HO}^{\bullet}(3)
\end{gathered}
$$

We used epithelial embryonic cell lines (EUE) comparing the wild type (pBD650) with the same line where the XPA gene was silenced by $80 \%$ (siXPA). Recently some of us have shown that EUE-siXPA cell lines are characterized by increased steady-state ROS levels and by an altered glutathione redox state as compared to wt [35]. By using EPR spectroscopy, the ROS levels in the EUE-siXPA cell line were found significantly increased with respect to their normal counterpart in a reaction catalyzed by transition metals [36]. In these two types of cells we tested the hypothesis that different degrees of lesions could be produced under different $\mathrm{O}_{2}$ tensions. In particular, we compared hypoxia $\left(1 \%\right.$ of $\left.\mathrm{O}_{2}\right)$ to physioxia and hyperoxia ( $5 \%$ and $21 \%$ of $\mathrm{O}_{2}$ respectively), in EUE-pBD650 (wt) and EUE-siXPA (deficient) cells. The levels of the four diastereomeric $5^{\prime}, 8$-cyclopurine lesions ( $5^{\prime} S$-cdG, $5^{\prime} R$-cdG, $5^{\prime} S$-cdA, and $5^{\prime} R$-dA), and the 8-oxo-Pu lesions (8-oxo-dG and 8-oxo-dA) were determined. Furthermore, in both cell lines the levels of copper $(\mathrm{Cu})$ and iron $(\mathrm{Fe})$ were quantified in order to indirectly establish the potential production of ROS levels in these cells, and support the hypothesis of functional connection among metal levels, hydroxyl radical generation and oxidative DNA damage accumulation in association with oxygen concentration. To monitor the cellular response of stress conditions due to hyperoxia $\left(21 \% \mathrm{O}_{2}\right)$, cell membrane compartment was considered using the fatty acid-based membrane lipidomic analysis [25,37], which is informative of lipid remodeling associated with DNA damage.

\section{Materials and Methods}

\subsection{Materials}

Nuclease P1 from Penicillium citrinum, phosphodieasterase I and II, alkaline phosphatase from bovine intestinal mucosa, DNase I and DNase II, benzonase 99\%, BHT, deferoxamine mesylate, 
and pentostatin were purchased from Sigma-Aldrich (Steinheim, Germany). RNase T1 was from Thermo Fisher Scientific (Waltham, MA, USA) and RNase A from Roche Diagnostic GmbH, (Mannheim, Germany). 2'-Deoxyadenosine monohydrate and 2'-Deoxyguanosine monohydrate were purchased from Berry \& Associates Inc. (Dexter, NY, USA). Isotopic labelled internal standards of $5^{\prime} R$-cdA, $5^{\prime} S$-cdA, $5^{\prime} R$-cdG, $5^{\prime} S$-cdG, 8-oxo-dA, and 8-oxo-dG were prepared according to the previously reported procedures [38]. Solvents (HPLC-grade) were purchased from Fisher Scientific (Waltham, MA, USA). The $3 \mathrm{kDa}$ cut-off filters were obtained from Millipore (Bedford, OH, USA).

\subsection{Cell Cultures}

The EUE-siXPA and EUE-pBD650 cell lines have been previously described [8]. Briefly, the EUE-siXPA cell line presents $80 \%$ silencing of the XPA gene and is hypersensitive to the killing effects of UV. Cells were cultured in Dulbecco's modified Eagle's medium (DMEM, Invitrogen Life Technologies S.r.l., Milan, Italy), supplemented with $10 \%$ fetal calf serum (Corning, NY, USA). Cell lines were cultured in a $\mathrm{CO}_{2}$ incubator (SeriesII Water Jacket 3131, Thermo Scientific, Waltham, MA, USA) at three different $\mathrm{O}_{2}$ concentrations $(1 \%, 5 \%$ and $21 \%)$ for two weeks.

\subsection{Genomic DNA Isolation}

Genomic DNA was isolated using a high-salt extraction method. A nuclei lysis buffer containing $10 \mathrm{mM}$ Tris- $\mathrm{HCl}, 7.5,400 \mathrm{mM} \mathrm{NaCl}, 2 \mathrm{mM}$ EDTA, 1\% SDS $(w / v), 200 \mu \mathrm{g} / \mathrm{mL}$ proteinase $\mathrm{K}, 0.1 \mathrm{mM}$ deferoxamine, $0.1 \mathrm{mM}$ butylated hydroxytoluene (BHT), was used to resuspend the cells $\left(1 \times 10^{7}\right.$ cells in $1 \mathrm{~mL}$ of lysis buffer) and the lysates were incubated at $55^{\circ} \mathrm{C}$ overnight. After $16 \mathrm{~h}, 360 \mu \mathrm{L}$ of saturated $\mathrm{NaCl}$ solution (12 $\mathrm{g}$ of $\mathrm{NaCl}$ and water until $50 \mathrm{~mL}$ final volume) was added and incubated at $55^{\circ} \mathrm{C}$ for $15 \mathrm{~min}$, then the mixture was centrifuged at maximum speed for $30 \mathrm{~min}$. The nucleic acids, in the supernatant, were precipitated with 2.5 volumes of absolute ethanol, incubated at $-20^{\circ} \mathrm{C}$ for $30 \mathrm{~min}$ and then centrifuged for $30 \mathrm{~min}$ at maximum speed. Nucleic acids were resuspended in a suitable volume and RNase A $(20 \mu \mathrm{g} / \mathrm{mL})$ was added. After $1 \mathrm{~h}$ incubation at $37^{\circ} \mathrm{C}$, an extraction step with an equal volume of chloroform/isoamyl alcohol $(24: 1, v / v)$ and ethanol precipitation steps were performed. After centrifugation at maximum speed for $10 \mathrm{~min}$, the resulting DNA pellet was washed twice with $70 \%$ cold ethanol, allowed to air-dry and resuspended in water.

\subsection{Enzymatic Digestion Protocol}

An aliquot of $10 \mu \mathrm{g}$ isolated DNA was dissolved in $100 \mu \mathrm{L}$ of Ar flushed $10 \mathrm{mM}$ Tris- $\mathrm{HCl}(\mathrm{pH}$ 7.9), containing $10 \mathrm{mM} \mathrm{MgCl}_{2}, 50 \mathrm{mM} \mathrm{NaCl}, 0.2 \mathrm{mM}$ pentostatin, $5 \mu \mathrm{M}$ BHT, and $3 \mathrm{mM}$ deferoxamine and the internal standards were added $\left(\left[{ }^{15} N_{5}\right]-5^{\prime} S\right.$-cdA, $\left[{ }^{15} N_{5}\right]-5^{\prime} R$-cdA, $\left[{ }^{15} N_{5}\right]-5^{\prime} S$-cdG, $\left[{ }^{15} N_{5}\right]-5^{\prime} R$-cdG, $\left[{ }^{15} N_{5}\right]-8$-oxo-dG and $\left[{ }^{15} N_{5}\right]-8$-oxo-dA) as previously described (see Figure S1) [25,31]. Benzonase (3 U in $20 \mathrm{mM}$ Tris- $\mathrm{HCl} \mathrm{pH}$ 8.0, $2 \mathrm{mM} \mathrm{MgCl} 2$ and $20 \mathrm{mM} \mathrm{NaCl}$ ), $4 \mathrm{mU}$ phosphodiesterase I, $3 \mathrm{U}$ DNAse I, $2 \mathrm{mU}$ of phosphodiesterase II and $2 \mathrm{U}$ of alkaline phosphatase were added and the mixture was incubated at $37^{\circ} \mathrm{C}$. After $21 \mathrm{~h}, 35 \mu \mathrm{L}$ of Ar flushed buffer containing $0.3 \mathrm{M} \mathrm{AcONa}(\mathrm{pH}$ 5.6) and $10 \mathrm{mM}$ $\mathrm{ZnCl}_{2}$ were added along with $0.5 \mathrm{U}$ of Nuclease P1 (in $30 \mathrm{mM} \mathrm{AcONa} \mathrm{pH} \mathrm{5.3,} 5 \mathrm{mM} \mathrm{ZnCl}_{2}$ and $50 \mathrm{mM}$ $\mathrm{NaCl}), 4 \mathrm{mU}$ PDE II and $125 \mathrm{mU}$ of DNAse II and the mixture was further incubated at $37^{\circ} \mathrm{C}$ for extra $21 \mathrm{~h}$. A step-quenching with $1 \%$ formic acid solution (final $\mathrm{pH} 7$ ) was followed, the digestion mixture was placed in a microspin filter $(3 \mathrm{kDa})$ and the enzymes were filtered off by centrifugation at $14,000 \times g\left(4^{\circ} \mathrm{C}\right)$ for $20 \mathrm{~min}$. Subsequently, the filtrate was freeze-dried before HPLC analysis, clean-up, and enrichment.

\subsection{Measurement of Modified Nucleosides by LC-MS/MS}

The samples were analyzed by an HPLC-UV system coupled with a sample collector, while the fractions containing the lesions were collected, freeze-dried, pooled, freeze-dried again, redissolved in Milli-Q water and subsequently injected to the LC-MS/MS system [13,38-40]. A triple-stage quadrupole mass spectrometer equipped with electrospray ionization (ESI) source in positive mode 
was employed for the detection and quantification of the lesions in the enzymatically digested DNA samples. The gradient elution program used for the chromatographic separation of the DNA lesions initiated with $99 \%$ of $2 \mathrm{mM}$ ammonium formate (solvent $\mathrm{A}$ ) and $1 \%$ acetonitrile (solvent B) (held for $1 \mathrm{~min}$ ), increasing solvent $B$ from $1 \%$ to $9.8 \%$ within $20 \mathrm{~min}$ and then immediately to $15 \%$ solvent $B$ (held for $5 \mathrm{~min}$ ), closing with initial conditions for $10 \mathrm{~min}$ re-equilibration. The flow rate remained constant at $0.2 \mathrm{~mL} / \mathrm{min}$, the injection volume was $30 \mu \mathrm{L}$ and the column temperature was set at $30^{\circ} \mathrm{C}$. Detection was performed in multiple reaction monitoring mode (MRM) using the two most intense and characteristic precursor/product ion transitions for each DNA lesion (Figure S2 and Table S1).

\subsection{Metals Quantification}

For determination of copper $(\mathrm{Cu})$ and iron $(\mathrm{Fe})$ the wt and XPA-defective EUE cell pellets were subjected to a mineralization cycle in ModBlock plate (ModBlock CPI International, Santa Rosa, CA, USA) with $100 \mu \mathrm{L}$ of $\mathrm{HNO}_{3}$ for $15 \mathrm{~min}$ at $60-70^{\circ} \mathrm{C}$ and, at the end, $400 \mu \mathrm{L}$ of ultra-pure deionized water (Barnstead EASY-PureII, Dubuque, IA, USA) were added. The quantification was performed using iCAP Q Inductively Coupled Plasma Mass Spectrometer (ICP-MS) equipped with the collision cell pressurized with He (Thermo Fisher Scientific, Bremen, Germany) in the KEDS mode. The instrument configuration and operation parameters are shown in Table S10. The ICAP Q was equipped with a PFA-ST MicroFlow nebulizer (ESI, Omaha, NB, USA), a Peltier cooled quartz spray chamber (operating at $3{ }^{\circ} \mathrm{C}$ ), a $2.0 \mathrm{~mm}$ ID sapphire injector and a demountable quartz torch with interface Ni sampler and skimmer.

Prior to the analysis a volume of $200 \mu \mathrm{L}$ was diluted (1:2 v/v) with ultra-pure deionized water and $\mathrm{Cu}$ and Fe quantification was carried out through calibration curve in the range $0.25-50 \mathrm{ng} / \mathrm{mL}$ for each element and using in as internal standard (IS) $(1 \mathrm{ng} / \mathrm{mL}$ in the analytical solutions). The calibrants and the IS solution were daily prepared from certified solutions of $1 \mathrm{mg} / \mathrm{mL}$ (CPAchem Ltd., Stara Zagora, Bulgaria). Accuracy of the analytical procedure was assessed using the Certified Reference Material (CRM) Seronorm Lyophilized Human Serum (Sero, Billingstad, Norway) at concentration level II, resulting in the range $82-84 \%$ for the two metals. Details about validation results are reported elsewhere [36].

The limit of detection (LoD) was calculated following the criterion of the 3 sigmas, analyzing 10 samples of the blank. The resulting LoDs for $\mathrm{Cu}$ and Fe were 0.072 and $0.734 \mathrm{ng} / \mathrm{mL}$, respectively.

\subsection{Lipid Extraction and Fatty Acid-Based Lipidomic Analysis}

Cell membrane phosholipids were isolated using the well-established Folch method [41]. Briefly, the pellet was re-suspended in pure water and lipids were extracted with 2:1 chloroform:methanol and examined by thin layer chromatography (n-hexane/diethyl ether/acetic acid 70/30/1) to determine the purity of the phospholipid fraction. The phospholipid extract was then treated with 0.5 $\mathrm{M} \mathrm{KOH} / \mathrm{MeOH}$ for $10 \mathrm{~min}$ at room temperature under stirring for the derivatization of fatty acid residues of the phospholipids into their corresponding fatty acid methyl esters (FAME). FAME were extracted with n-hexane, n-hexane phase was dehydrated with anhydrous $\mathrm{Na}_{2} \mathrm{SO}_{4}$, evaporated and analyzed by Agilent 7890B CG system equipped with a $60 \mathrm{~m} \times 0.25 \mathrm{~mm} \times 0.25 \mu \mathrm{m}$ (50\%-cyanopropyl)-methylpolysiloxane column (DB23, Agilent, Santa Clara, CA, USA), a flame ionization detector (FID), with injector temperature at $230^{\circ} \mathrm{C}$ and split injection 50:1. Oven temperature started from $165^{\circ} \mathrm{C}$, held for $3 \mathrm{~min}$, followed by an increase of $1^{\circ} \mathrm{C} / \mathrm{min}$ up to $195^{\circ} \mathrm{C}$, held for $40 \mathrm{~min}$, followed by a second increase of $10^{\circ} \mathrm{C} / \mathrm{min}$ up to $240^{\circ} \mathrm{C}$, and held for $10 \mathrm{~min}$. A constant pressure mode ( $29 \mathrm{psi}$ ) with helium as the carrier gas was used. Methyl esters were identified by comparison with the retention times of commercially available standards or trans fatty acid references, obtained as described elsewhere) as described previously [42]. 


\subsection{Statistical Analysis}

All measurements were performed in triplicate and the data were expressed as mean \pm standard deviation (SD). The unpaired $t$-test was used for statistical analysis and a two-tailed $p$-value $<0.05$ and $p$-value $<0.005$ were considered to indicate a statistically significant difference.

\section{Results}

\subsection{Levels of cPu and 8-oxo-Pu in DNA Samples}

LC-MS/MS analysis revealed that both EUE-pBD650 (wt) and EUE-siXPA (deficient) cells accumulated high levels of $\mathrm{cPu}$ under hypoxic conditions (1\%) compared with physioxic (5\%) and hyperoxic conditions (21\%) (Figure 3). In Supplementary Materials Table S2, Table S3, and Table S4 collected all the experimental values and statistical analysis. Under all different oxygen concentrations, the $5^{\prime} S$-cdG was found the most predominant with detected levels of 0.92-1.03/106 nucleosides in wt cells and 0.93-1.20/106 nucleosides in deficient ones (see Tables S2 and S3). Significantly elevated levels of $5^{\prime} R$-cdG ( $\left.p=0.033\right)$ and $5^{\prime} R$-cdA $(p=0.032)$ were observed in EUE-pBD650 cells under hypoxia (blue bars vs. orange bars) while $5^{\prime} R$-cdA, $5^{\prime} S$-cdG and $5^{\prime} S$-cdA were found significantly increased in EUE-siXPA cells under hypoxic conditions ( $p=0.037, p=0.002, p=0.020$, respectively). It is worth underling that, in EUE-siXPA cells, we found statistically significant alterations comparing physioxic and hypoxic conditions in the levels of $5^{\prime} R-\operatorname{cdA}(p=0.028), 5^{\prime} S-\mathrm{cdG}(p=0.025)$ and $5^{\prime} S-\operatorname{cdA}(p=0.003)$ in EUE-siXPA cells (Figure 3). Moreover, comparison of wild type and deficient cell lines, revealed statistically significant differences have been indicated in the levels of $5^{\prime} R$-cdG $(p=0.019)$ and $5^{\prime} R$-cdA ( $p=0.022)$ under hyperoxic conditions (blue bars $v$ s orange bars) as well as in the levels of $5^{\prime} S$-cdG $(p=0.013)$ under hypoxic conditions (blue bar vs orange bar, Figure 3$)$. 


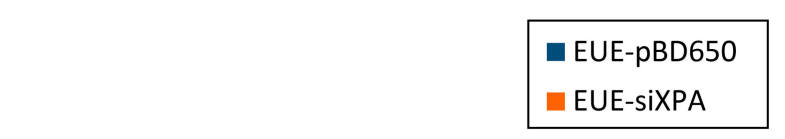

8-oxo-dG
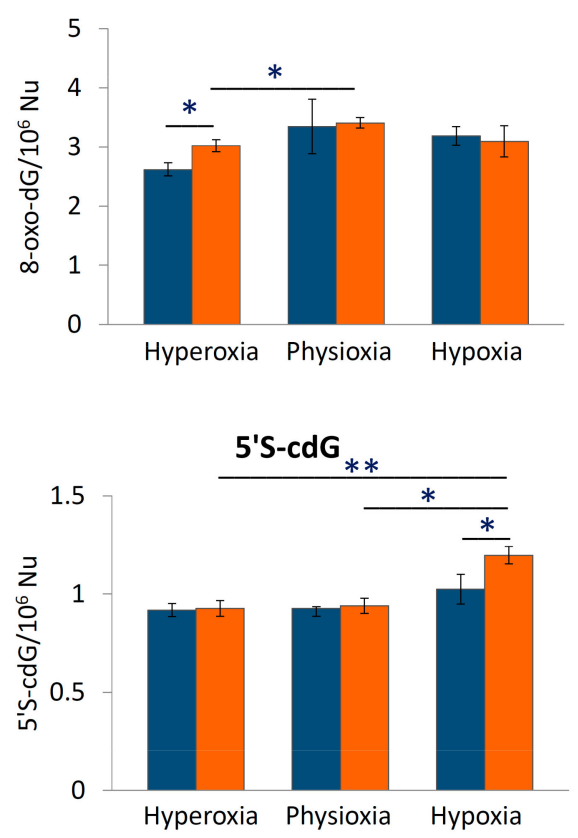

5'R-cdG



8-oxo-dA

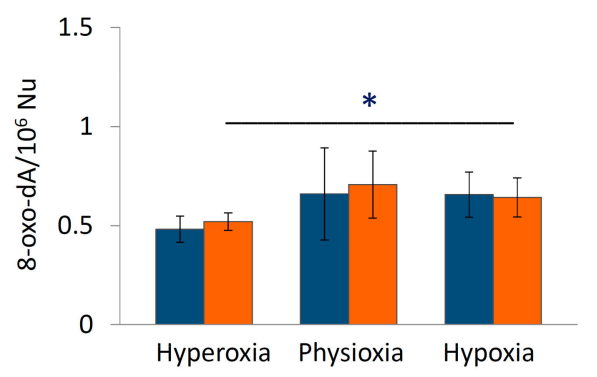

5'S-cdA

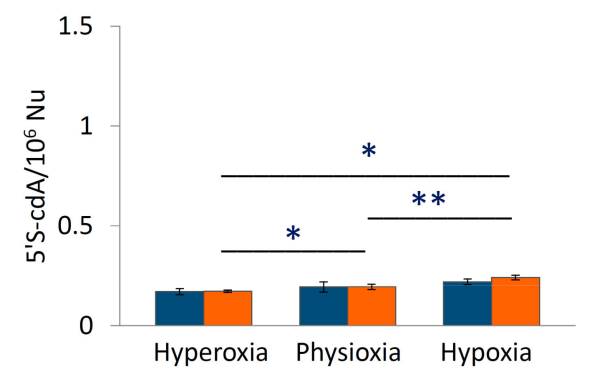

$5^{\prime} R-\operatorname{cdA}$

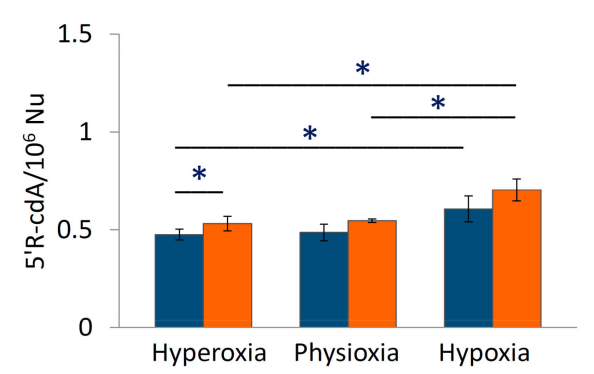

Figure 3. The levels (lesions $/ 10^{6}$ nucleosides) of 8-oxo-dG and 8-oxo-dA, $5^{\prime} R$-cdG, $5^{\prime} S$-cdG, $5^{\prime} R$-cdA and 5'S-cdA in DNA samples isolated from EUE-pBD650 and EUE-siXPA (wt and deficient, respectively) cells in hyperoxic, physioxic and hypoxic conditions. Error bars: standard deviation of the mean, calculated from three independent samples, ${ }^{*}$ : statistically significant difference $(p<0.05)$ between the groups, $^{* *}$ : statistically significant difference $(p<0.005)$ between the groups.

Figure 3 also illustrates the levels of 8-oxo-Pu (8-oxo-dG and 8-oxo-dA) in genomic DNA isolated from EUE-pBD650 and EUE-siXPA cells in physioxic, hyperoxic and hypoxic conditions (Table S2 and $\mathrm{S} 3$ collect the levels of 8-oxo-Pu). The 8-oxo-dG level was found significantly elevated in deficient cells compared to the wild type cell line $(p=0.015)$ in hyperoxic conditions (blue bars vs. orange bars). Moreover, EUE-siXPA cells are characterized by a significant enhancement of this lesion comparing hyperoxic and physioxic conditions $(p=0.042)$. Furthermore, deficient cells significantly accumulated 8-oxo-dA under hypoxic conditions $(p=0.033)$.

Total 8-oxo-Pu levels were determined approximately 1.5-2-fold more elevated compared with total $\mathrm{cPu}$ as illustrated in Figure 4 (see Table S5 for detailed values). For the first type of lesions (8-oxo-dG), statistically, significant differences were found under hyperoxic conditions among wild type and deficient cells $(p=0.002)$ as well as among hyperoxia and physioxia both in EUE-pBD650 and EUE-siXPA cells ( $p=0.026$ and 0.001 , respectively. See Table S6 for detailed values). On the other 
side, total $\mathrm{cPu}$ have been observed statistically significant higher in deficient cell lines than wt cells under hyperoxic $(p=0.027)$ and hypoxic conditions $(p=0.009)$. Moreover, the levels of these lesions were identified significantly altered in EUE-pBD650 cells comparing hyperoxia and hypoxia $(p=0.047)$ and in EUE-siXPA cells among physioxia and hypoxia $(p=0.037)$, as presented in Table S6. It should be highlighted the statistical significance among total $\mathrm{cPu}$ and 8-oxo-Pu and oxygen concentration, statistically significant alterations have been found either in wild type cell line under hyperoxia $(p=0.009)$, physioxia $(p=0.016)$ and hypoxia $(p=0.001)$ or in deficient cell $(p=0.005$ for hyperoxia, $p=0.001$ for physioxia, $p=0.016$ for hypoxia (Table S7).

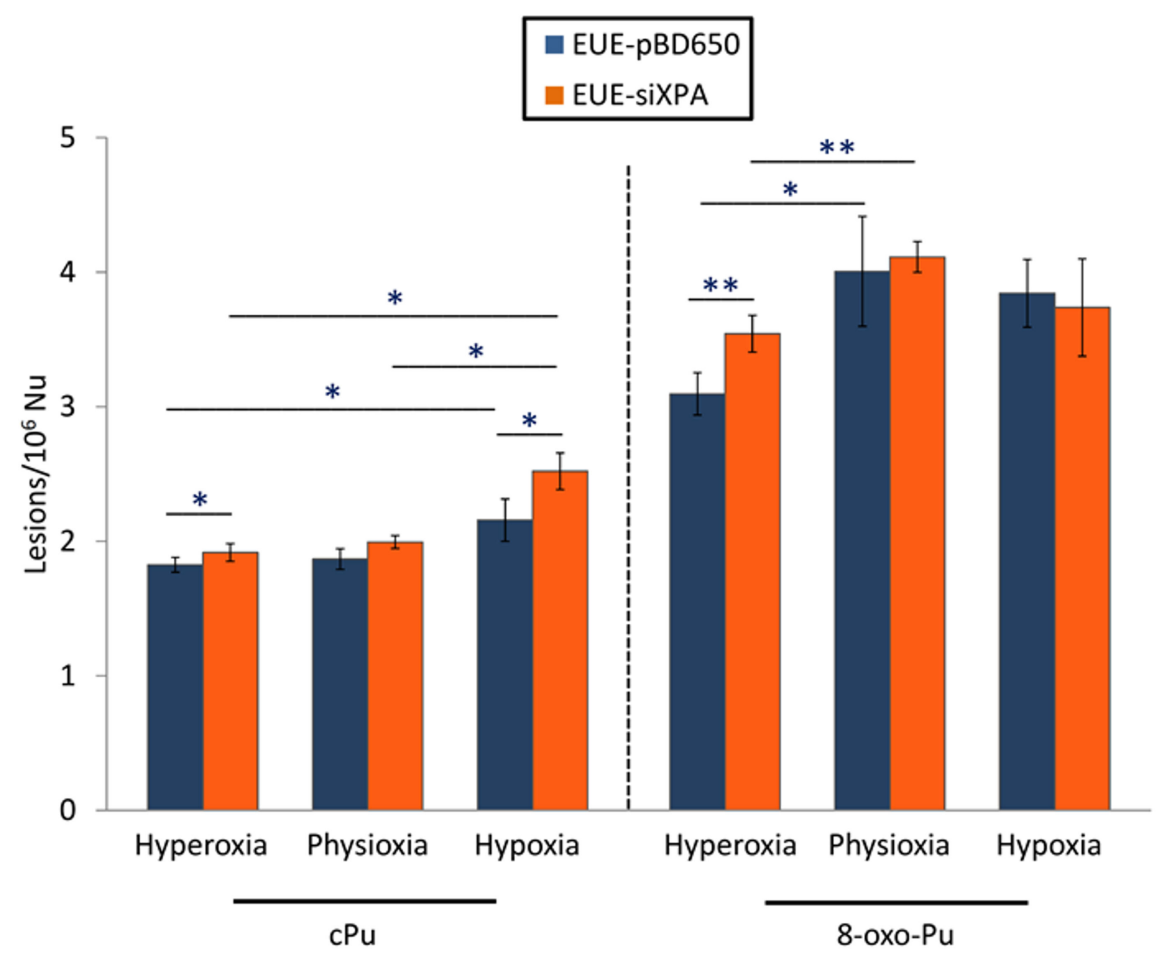

Figure 4. The levels (lesions $/ 10^{6}$ nucleosides) of sum of cyclopurine and 8-oxo-purine lesions in DNA isolated from EUE-pBD650 (wt) and EUE-siXPA (deficient) cells in in hyperoxic, physioxic and hypoxic conditions. Error bars: standard deviation of the mean, calculated from three independent samples, *: statistically significant difference $(p<0.05)$ between the groups, ${ }^{* *}$ : statistically significant difference $(p<0.005)$ between the groups.

In Table S8, Table S9 and Figure S3, the levels of cdG and cdA together with 8-oxo-dG and 8-oxo-dA lesions in both EUE-pBD650 and EUE-siXPA cells under the three distinct experimental conditions are presented. cdG lesions values were found approximately 1-fold higher compared with $\mathrm{cdA}$ levels either in wild type or in a deficient cell line. Among hyperoxia and hypoxia statistically significant alterations have been observed in deficient cells for cdG $(p=0.010), \operatorname{cdA}(p=0.012)$ and 8-oxo-dA ( $p=0.033)$ as well as in wild type cells for cdA $(p=0.037)$. It should be highlighted that EUE-siXPA cells accumulated higher levels of both cyclopurines compared to EUE-pBD650 cells under hypoxic conditions ( $p=0.009$ for $\mathrm{cdG}, p=0.008$ for $\mathrm{cdA}$. Similar trend was followed under hyperoxic conditions for cdA ( $p=0.033)$ and 8-oxo-dG $(p=0.015)$ (Tables S8 and S9).

In Table 1 , the ratios of $5^{\prime} R / 5^{\prime} S$ for $c d G$ and cdA in DNA isolated from wt and deficient cells under hyperoxic, physioxic and hypoxic conditions are reported as additional information on structural features associated to the two different diastereisomeric lesions, which are studied for their significance in the formation and repair of these lesions. The $5^{\prime} R / 5^{\prime} S$ ratio is almost the same for $\mathrm{cdG}$ and $\mathrm{cdA}$ lesions under the three distinct experimental conditions, with a slight increase going from wt to deficient cell lines, being cdA approximately 9-folds higher than the corresponding value of cdG. 
Table 1. $5^{\prime} R / 5^{\prime} S$ ratio of cPu lesions in DNA isolated from EUE-pBD and EUE-siXPA cells in hyperoxic, physioxic and hypoxic conditions.

\begin{tabular}{cccc}
\hline Samples & Conditions & $\begin{array}{c}\text { cdG } \\
\mathbf{5}^{\prime} \mathbf{R} / \mathbf{5}^{\prime} \mathbf{S}\end{array}$ & $\begin{array}{c}\text { cdA } \\
\mathbf{5}^{\prime} \mathbf{R} / \mathbf{5}^{\prime} \mathbf{S}\end{array}$ \\
\hline EUE-pBD650 & Hyperoxic & $0.29 \pm 0.01$ & $2.80 \pm 0.38$ \\
EUE-pBD650 & Physioxic & $0.28 \pm 0.03$ & $2.51 \pm 0.18$ \\
EUE-pBD650 & Hypoxic & $0.30 \pm 0.01$ & $2.77 \pm 0.35$ \\
EUE-siXPA & Hyperoxic & $0.31 \pm 0.01$ & $3.09 \pm 0.30$ \\
EUE-siXPA & Physioxic & $0.33 \pm 0.04$ & $2.81 \pm 0.19$ \\
EUE-siXPA & Hypoxic & $0.32 \pm 0.03$ & $2.92 \pm 0.29$ \\
\hline
\end{tabular}

\subsection{Iron and Copper Levels in XPA Cells}

As additional information connected with the role of transition metals in the radical-based biological reactivity, the levels of iron and copper in XPA-defective cells and in their normal counterpart have been quantified, following previously reported methods [43-45]. Analysis of experimental data indicated that Fe levels, but not $\mathrm{Cu}$ levels, are significantly higher $(\mathrm{p}<0.05)$ in XPA-defective compared to wt cells (Figure 5).



Figure 5. Iron and copper levels in XPA-defective cells and in their normal counterpart, quantified by ICP-MS.

\subsection{Lipidomic Analysis of EUE-pBD650 and EUE-siXPA Cells Grown at 21\% Oxygen}

To investigate the role of membrane lipids, we have analyzed membrane fatty acid composition of EUE-pBD650 and EUE-siXPA cells. Stress conditions are known to induce the fatty acid remodeling according to the Land's cycle [46], therefore it is relevant to understand which are the differences between wt and deficient cells. Following known methodologies for the membrane pellet formation, phospholipid isolation and transesterification we obtained fatty acid methyl esters (FAME), analyzed by gas chromatography (GC). The methods used in this work for GC analysis have been described elsewhere [37,47]. Three samples for each group were analyzed. Tables S11 and S12 indicate the membrane fatty acid composition, the main membrane fatty acid families and the fatty acid indexes were calculated from these values. Fatty acid quantities are reported as relative percentages of the main peak areas obtained from the GC analyses, calibrated and recognized with appropriate references, as already described [25,48]. In Figures 6 and 7 the main fatty acids and families together with the indexes are graphically represented as percentage differences, obtained by comparing wild type (EUE-pBD650) and deficient (EUE-siXPA) cells, with their statistical significance. Table S12 depicts the levels of each fatty acid type present in the membrane phospholipids of the two cell lines. For saturated fatty acids (SFA) statistically significant decrease of myristic (14:0), palmitic (16:0) and stearic (18:0) acid residues was observed comparing EUE-pBD650 to EUE-siXPA cells $(p<0.05, p<0.01, p<0.01$, respectively). On the other hand, the level of monounsaturated fatty acids (MUFA) was increased in deficient cells as shown for 9c-16:1 (palmitoleic acid) and 9c-18:1 (oleic acid) (9c-16:1, $p<0.001,9 c-18: 1, p<0.05$ ). The decrease of 11c-18:1 (vaccenic, $p<0.01$ ) was observed (Figure 6). In the polyunsaturated fatty 
acid (PUFA) omega-3 series, EPA ( $5 c, 8 c, 11 c, 14 c, 17 c-20: 5)$ was found distinctly enhanced in EUE-siXPA compared with wild type cells $(p<0.01)$, whereas DPA $(7 c, 10 c, 13 c, 16 c, 19 c-22: 5)$ was significantly decreased $(p<0.01)$ and DHA levels remain undisturbed. However, the total omega-3 PUFA content in membrane phospholipids did not change. No significant changes were found in the PUFA omega-6 and trans isomers. The variation found in MUFA led to the increase of the unsaturation index (UI) of EUE-siXPA cell lines compared to EUE-pBD650 cells $(p<0.05)$ (cfr., Table S12 and Figure 7).

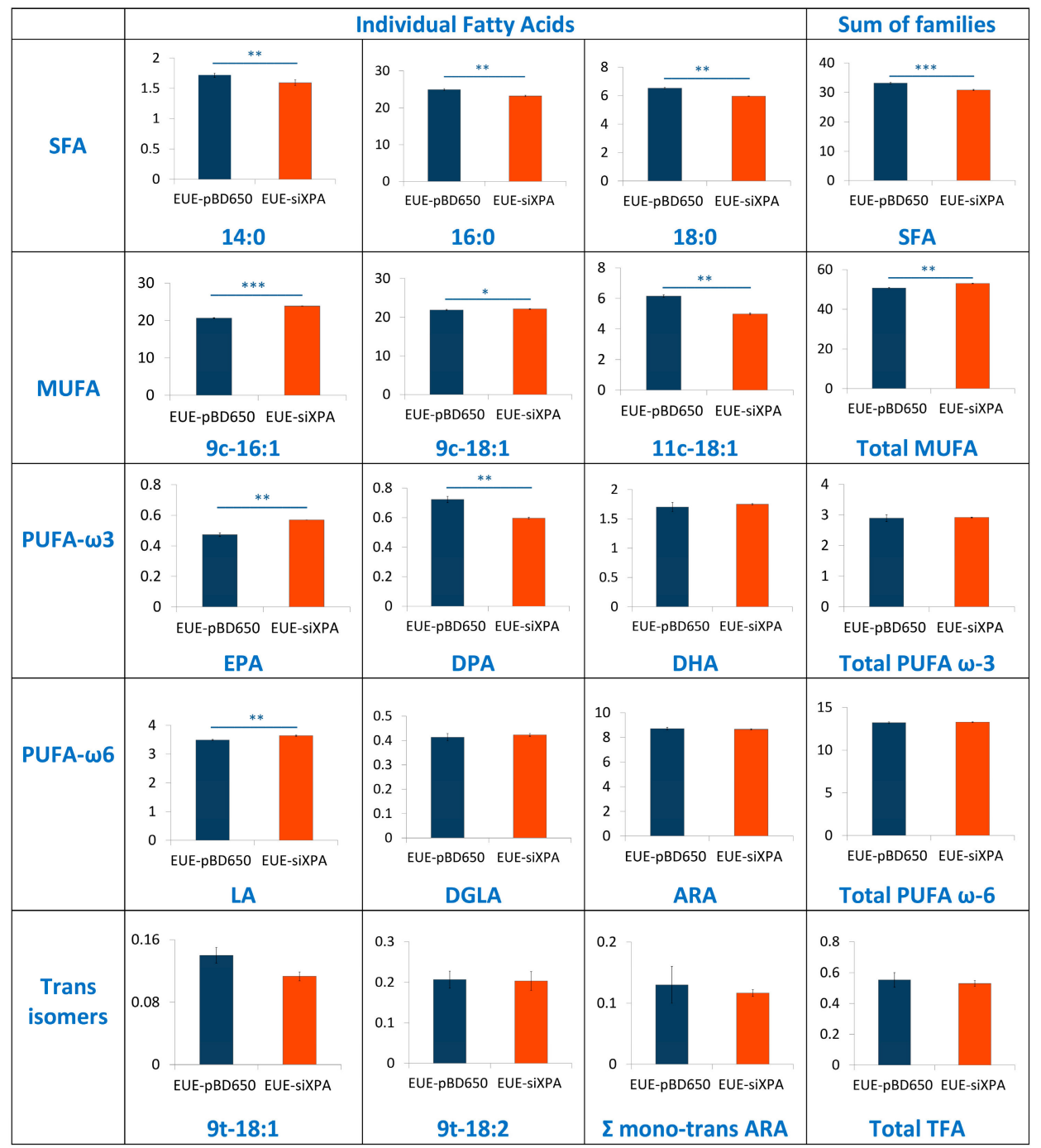

Figure 6. Percentage differences presenting comparison between EUE-pBD650 (wt) and EUE-siXPA cell membranes. The values are given as mean $\pm \operatorname{SD}(n=3)$. Each member of the fatty acid family is given in a row, the last column is the sum of the corresponding fatty acid family. Values significantly different from wt cells: $\left(^{*}\right) p<0.05,\left({ }^{* *}\right) p<0.01,\left({ }^{* *}\right) p<0.001$. For specific values see Table S12. Asterisks indicate the significance of differences between wt and deficient cells. 


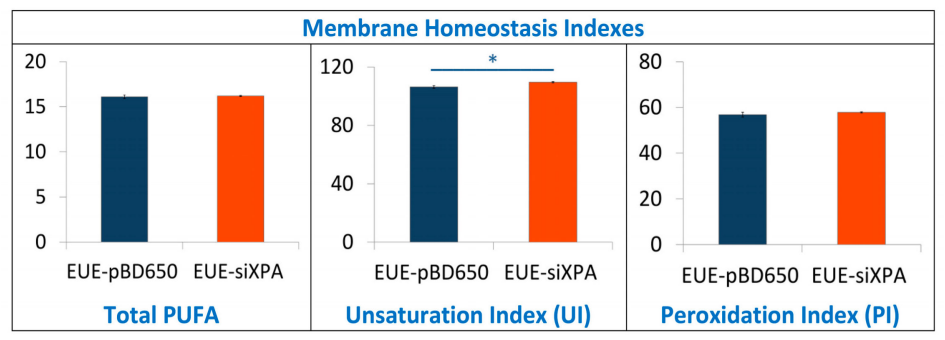

Figure 7. Membrane homeostasis indexes in EUE-pBD650 (wt) and EUE-siXPA cells. The values are given as mean \pm SD $(n=3)$. Values significantly different from EUE-pBD650 cells: $\left(^{*}\right) p<0.05$, For specific values see Table S12.

\section{Discussion}

In this article, we analyzed three biochemical features comparing the wild type human epithelial embryonic cell line (pBD650-EUE) with its XPA-deficient counterpart (EUE-siXPA), characterized by $80 \%$ silencing of XPA and so defective in nucleotide excision repair system. Under normal oxygen incubation conditions $\left(21 \% \mathrm{O}_{2}\right)$, we analyzed levels of metals (iron and copper) and membrane fatty acid balance, whereas we measured genomic DNA damage expressed as levels of cPu and 8-oxo-Pu lesions by varying oxygen concentration $\left(21 \%, 5 \%\right.$ and $\left.1 \% \mathrm{O}_{2}\right)$. With the first two information we could get some insights into two important compartments contributing to cell stress response and cooperating in reactivity to and signaling of the overall damage to DNA. For what concern to metals, it is known that, in order to avoid its heavy toxicity, iron homeostasis is accurately controlled by cells, finely regulating its absorption, recycling and mobilization by specific intracellular storage. However, pathological conditions involving oxidative stress have been reported to favor the release of free iron from metal-containing molecules [32,49]. This event leads in turn to the amplification of ROS release, including the formation of strong oxidant species, including $\mathrm{HO}^{\bullet}$ radical. The high reactivity and the short half-life make ${ }^{\bullet} \mathrm{OH}$ the most reactive and toxic oxidant species able to react with almost all biological molecules (proteins, lipids, carbohydrates, and nucleic acids). We found that XPA defective cells have a high Fe content compared to wt cells, which can indicate an unbalance of Fe homeostasis and higher propensity to oxidative damage than normal cells. We carried out also an evaluation of membrane lipid response to $21 \% \mathrm{O}_{2}$ conditions, using the fatty acid monitoring of membrane phospholipids by a well-known methodology for isolation, work-up, and GC analysis. The differences in membrane lipidomic data between the wild type and XPA-defective cells pointed the attention to metabolic changes that involve the desaturase enzymatic step (stearoyl CoA-desaturase, SCD1). In fact, the increase of MUFA is due to the activation of such enzymatic pathway using the SFA pool, in particular palmitic and stearic acids which are correspondently diminished.

Desaturase enzymes use iron and oxygen as their cofactors for the double bond formation [50] and it is remarkable that we found iron levels higher in XPA-defective cells (see Figure 3). The increase of MUFA and the correspondent UI level could also produce other changes in the membrane asset and properties, increasing for example membrane fluidity. The increased fluidity with change of unsaturation is in relationship with stress signaling in cells [51] and higher ROS production is a well-known stress condition where cells can activate several responses [52]. Indeed, by the changes observed in our case, we could estimate that cell membrane is a significant "tool" to evaluate stress response. In the same conditions, the levels of all DNA lesions were significant (see Figure 4), thus underlining that different compartments must be evaluated in order to have a holistic view of the stress response. Our results also suggest that the parallel analyses of DNA-membrane compartments can be used in DNA repair enzyme-defective cells, to better understand connections with signaling cascades departing from membrane lipids, taking into account that in our case changes for the omega-3 and not for the omega- 6 fatty acids were seen.

The core experiments of this paper concerned the accurate cPu lesions' determination and quantification under different oxygen conditions. It is worth underlining that usually $21 \%$ oxygen is 
used as "normoxic" incubation condition, but we evaluated this condition as "hyperoxia". As pointed out by Al-ani et al. [53], the information on the oxygen concentration in cell culture incubation is a relevant aspect to detail in the experimental methodology. In fact, our results contribute to a better understanding of the role of oxygen incubation conditions when DNA damage and repair abilities are involved. A second methodological point to remark is the individuation of the best analytical strategy including the experimental procedures for DNA extraction, hydrolysis, and derivatization. Our protocol for the quantification of $\mathrm{cPu}$ lesions via LC-ESI-MS/MS, in particular using isotopic labeled lesions (Figure S1), enhances the reliability of the analysis and increases to a great extent the characteristics of reproducibility and recovery of the quantification protocol $[13,38]$. The main findings of our study were: (i) the four $\mathrm{cPu}$ levels are similar in hyperoxic and physioxic conditions for both wt and deficient cell lines, whereas 8-oxo-Pu increases in all cases, (ii) both wt and deficient cell lines accumulated high levels of $\mathrm{cPu}$ under hypoxic compared to physioxic conditions, whereas the 8-oxo-Pu levels show an opposite trend, (iii) the diastereoisomeric ratios $5^{\prime} R / 5^{\prime} S$ are independent of oxygen concentration being 0.29 for cdG and 2.69 for cdA for EUE-pBD650 (wt) and 0.32 for cdG and 2.94 for cdA for EUE-siXPA (deficient), see Table 1. Our data show for the first time the connection between oxygen concentration and DNA repair highlights of different lesions in XPA-deficient conditions and contribute to highlight the significance of $\mathrm{cPu}$.

In this paper, the use of XPA defective cells allowed for targeting the ability of DNA repair and this was estimated under three oxygen concentrations, where $1 \%$ and $21 \%$ represent the hypoxia and hyperoxia conditions compared to $5 \% \mathrm{O}_{2}$. cPu were confirmed to be a reliable marker of the oxygen tension, being their levels increased when hypoxia conditions are used. However, it is also important that when there is an NER defective condition the levels of the $\mathrm{cPu}$ lesions are increased thus in agreement with the fact that they are specific markers in NER defective diseases. On the other hand, 8-oxo-Pu lesions are less specific, being repaired by BER and derived in minor quantity from $\mathrm{HO}$ radicals and in major quantity from other oxidizing species like $\mathrm{H}_{2} \mathrm{O}_{2}$, peroxyl radicals, single oxygen, $\mathrm{ONOO}^{-}$etc., which can be activated under hypoxia conditions. It is worth mentioning that our defective cell line was $80 \%$ silenced for repair enzymatic capability, therefore a certain amount of repair can occur.

Regarding the $\mathrm{cPu}$ diastereoisomers, the $5^{\prime} R / 5^{\prime} S$ ratio was found to be higher in $\mathrm{cdA}$ than in $\mathrm{cdG}$ in both cell lines and at all the tested $\mathrm{O}_{2}$ concentrations. Moreover, starting from the knowledge that $5^{\prime} S$-cdG is a better NER substrate than $5^{\prime} S$-cdA lesion [14-16], this can explain the significant differences found in our experiments between these two markers in XPA-silenced cells (Figure 3). Working with HeLa cells, it was observed that $5^{\prime} R$-cdA and $5^{\prime} R$-cdG are better NER substrates that the $5^{\prime} S$-ones, while molecular dynamic simulations studies confirmed that the $R$-stereoisomers are significantly more dynamic and more distorting that the $S$-stereoisomeric lesions [14-16]. This result in the diastereomeric accumulation is different from the HeLa cells and breast cancer cells indicating that the DNA repair systems can have different specificity depending on tissue types. We recall that quantification of the four $\mathrm{CPu}$ lesions has been previously determined in estrogen receptor-alpha positive (ER-a) MCF-7 and triple negative MDA-MB-231 breast cancer cell lines before and after exposure to two different conditions: ionizing radiations and hydrogen peroxide, followed by an interval period to allow DNA repair [39]. The higher levels accumulation of 5'S-cdG in MDA-MB-231 and MCF-7 cells were in accordance with NER efficiencies [39].

\section{Conclusions}

In this work we show for the first time the connection of oxygen concentration in DNA repair-deficient cells, highlighting the quantity and quality of purine lesions. In particular, we checked the levels of $\mathrm{cPu}$, specific markers of $\mathrm{HO}^{\bullet}$ radical damage, and the 8-oxo-Pu which can be derived from other oxidizing species. The presence of a high Fe content in XPA defective cells (EUE-siXPA) can be an important indicator of the propensity to give an intense cellular stress response. Lipidomic monitoring of cell membrane under hyperoxic conditions and the resultant enhancement of MUFA 
together with the correspondent UI levels indicate for the first time that specific lipidome membrane alteration occurs under XPA-deficient conditions. Our results reveal a combined scenario between membrane lipid remodeling and oxidatively-induced DNA adducts under variable radical reactivity and stress status.

Supplementary Materials: The following are available online at http://www.mdpi.com/2073-4409/8/11/1377/s1, Figure S1: ${ }^{15} \mathrm{~N}_{5}$ isotopically labeled of cPu and 8-oxo-Pu, Figure S2: Calibration curves for the quantification of the lesions, Figure S3: The levels of cPu and 8-oxo-Pu lesions in DNA isolated from EUE-pBD650 (wt) and EUE-siXPA (deficient) cells in hyperoxic, physioxic and hypoxic conditions, Table S1: A list of MRM transitions employed for the quantifications of DNA lesions and their corresponding stable isotope-labeled standards, Table S2 and Table S3: The levels of cPu and 8-oxo-Pu in DNA samples isolated from EUE-pBD650 (wt) and EUE-siXPA (deficient) cells in hyperoxic, physioxic and hypoxic conditions, Table S4: Values of $\mathrm{t}$-Test by comparing the means of lesions in each condition, Table S5: Total amount of cPu and 8-oxo-Pu lesions in DNA isolated from EUE-pBD650 and EUE-siXPA cells in hyperoxic, physioxic and hypoxic conditions, Table S6: Values of $t$-Test by comparing the means of lesions in each condition, Table S7: Values of $t$-Test by comparing the sum of $\mathrm{cPu}$ and 8-oxo-Pu in each condition, Table S8: Total amount of cPus and 8-oxo-purine lesions in DNA isolated from EUE-pBD650 and EUE-siXPA cells in in hyperoxic, physioxic and hypoxic conditions, Table S9: Values of $t$-Test by comparing the means of lesions in each condition. Table S10: Instrument configuration and operation parameters of iCAP Q Inductively Coupled Plasma Mass Spectrometer (ICP-MS) equipped, Table S11: Fatty acids obtained from EUE-pBD650 (wt) and EUE-siXPA cell membrane phospholipids, Table S12: Relative percentage of fatty acid methyl esters and families from EUE-pBD650 $(\mathrm{wt})$ and EUE-siXPA.

Author Contributions: C.C. conceptualization and work coordination; E.P., M.D., B.P., A.P., A.A., and D.P. performed cell cultures; E.P., M.D., B.P., and A.M. collected samples; M.G.K. and A.M. worked-up samples; M.G.K. performed the LC-MS/MS analyses; A.P. performed metal quantification; Data Analysis, C.C., M.G.K., and C.F;; All authors contributed writing-original draft preparation; All authors contributed to the figures; All authors reviewed the manuscript.

Funding: This research was partially funded by the Marie Skłodowska-Curie European Training Network (ETN) ClickGene: Click Chemistry for Future Gene Therapies to Benefit Citizens, Researchers and Industry [H2020-MSCAETN-2014-642023] and by MIUR: “Ubiquitin E3 ligases as critical sensors in physiological and pathological conditions" PRIN, Prot. 20152CB22L.

Acknowledgments: We are grateful to Maria Louka for technical support in lipid analysis.

Conflicts of Interest: The authors declare no conflict of interest.

\section{References}

1. DiGiovanna, J.J.; Kraemer, K.H. Shining a light on xeroderma pigmentosum. J. Invest. Dermatol. 2012, 132, 785-796. [CrossRef]

2. Anttinen, A.; Koulu, L.; Nikoskelainen, E.; Portin, R.; Kurki, T.; Erkinjuntti, M.; Jaspers, N.G.; Raams, A.; Green, M.H.; Lehmann, A.R.; et al. Neurological symptoms and natural course of xeroderma pigmentosum. Brain 2008, 131, 1979-1989. [CrossRef]

3. Spivak, G. Nucleotide excision repair in humans. DNA Repair 2015, 36, 13-18. [CrossRef]

4. Nouspikel, T. DNA repair in differentiated cells: Some new answers to old questions. Neuroscience 2007, 145, 1213-1221. [CrossRef]

5. D'Errico, M.; Parlanti, E.; Dogliotti, E. Mechanism of oxidative DNA damage repair and relevance to human pathology. Mutat. Res. 2008, 659, 4-14. [CrossRef]

6. Fortini, P.; Dogliotti, E. Base damage and single-strand break repair: Mechanisms and functional significance of short- and long-patch repair subpathways. DNA Repair 2007, 6, 398-409. [CrossRef] [PubMed]

7. D’Errico, M.; Parlanti, E.; Teson, M.; de Jesus, B.M.; Degan, P.; Calcagnile, A.; Jaruga, P.; Bjørås, M.; Crescenzi, M.; Pedrini, A.M.; et al. New functions of XPC in the protection of human skin cells from oxidative damage. EMBO J. 2006, 25, 4305-4315. [CrossRef] [PubMed]

8. D’Errico, M.; Parlanti, E.; Teson, M.; Degan, P.; Lemma, T.; Calcagnile, A.; Iavarone, I.; Jaruga, P.; Ropolo, M.; Pedrini, A.M.; et al. The role of CSA in the response to oxidative DNA damage in human cells. Oncogene 2007, 26, 4336-4343. [CrossRef] [PubMed]

9. Parlanti, E.; D'Errico, M.; Degan, P.; Calcagnile, A.; Zijno, A.; van der Pluijm, I.; van der Horst, G.T.; Biard, D.S.; Dogliotti, E. The cross talk between pathways in the repair of 8-oxo-7,8-dihydroguanine in mouse and human cells. Free Radic. Biol. Med. 2012, 53, 2171-2177. [CrossRef] [PubMed] 
10. Chatgilialoglu, C.; Ferreri, C.; Terzidis, M.A. Purine 5' , 8-cyclonucleoside lesions: Chemistry and biology. Chem. Soc. Rev. 2011, 40, 1368-1382. [CrossRef]

11. Jaruga, P.; Dizdaroglu, M. 8,5'-Cyclopurine-2'-deoxynucleosides in DNA: Mechanisms of formation, measurement, repair and biological effects. DNA Repair 2008, 7, 1413-1425. [CrossRef] [PubMed]

12. Brooks, P.J. The cyclopurine deoxynucleosides: DNA repair, biological effects, mechanistic insights, and unanswered questions. Free Radic.Biol. Med. 2017, 107, 90-100. [CrossRef] [PubMed]

13. Chatgilialoglu, C.; Ferreri, C.; Geacintov, N.E.; Krokidis, M.G.; Liu, Y.; Masi, A.; Shafirovich, V.; Terzidis, M.A.; Tsegay, P.S. 5',8-Cyclopurine lesions in DNA damage: Chemical, analytical, biological and diagnostic significance. Cells 2019, 8, 513. [CrossRef] [PubMed]

14. Kropachev, K.; Ding, S.; Terzidis, M.A.; Masi, A.; Liu, Z.; Cai, Y.; Kolbanovskiy, M.; Chatgilialoglu, C.; Broyde, S.; Geancitov, N.E.; et al. Structural basis for the recognition of diastereomeric 5',8-cyclo-2'-deoxypurine lesions by the human nucleotide excision repair system. Nucl. Acids Res. 2014, 42, 5020-5032. [CrossRef] [PubMed]

15. Cai, Y.; Kropachev, K.; Terzidis, M.A.; Masi, A.; Chatgilialoglu, C.; Shafirovich, V.; Geancitov, N.E.; Broyde, S. Differences in the access of lesions to the nucleotide excision repair machinery in nucleosomes. Biochemistry 2015, 54, 4181-4185. [CrossRef]

16. Shafirovich, V.; Kolbanovskiy, M.; Kropachev, K.; Liu, Z.; Cai, Y.; Terzidis, M.A.; Masi, A.; Chatgilialoglu, C.; Amin, S.; Dadali, A.; et al. Nucleotide excision repair and impact of site-specific 5 ', 8 -cyclopurine and bulky DNA lesions on the physical properties of nucleosomes. Biochemistry 2019, 58, 561-574. [CrossRef]

17. Brooks, P.J.; Wise, D.S.; Berry, D.A.; Kosmoski, J.V.; Smerdon, M.J.; Somers, R.L.; Mackie, H.; Spoonde, A.Y.; Ackerman, E.J.; Coleman, K.; et al. The oxidative DNA lesion 8,5'-(S)-cyclo-2'-deoxyadenosine is repaired by the nucleotide excision repair pathway and blocks gene expression in mammalian cells. J. Biol. Chem. 2000, 275, 22355-22362. [CrossRef]

18. Kuraoka, I.; Bender, C.; Romieu, A.; Cadet, J.; Wood, R.D.; Lindahl, T. Removal of oxygen free-radical induced 5',8-purine cyclodeoxynucleosides from DNA by the nucleotide excision-repair pathway in human cells. Proc. Natl. Acad. Sci. USA 2000, 97, 3832-3837. [CrossRef]

19. Theruvathu, J.A.; Jaruga, P.; Dizdaroglu, M.; Brooks, P.J. The oxidatively induced DNA lesions 8,5'-cyclo-2'-deoxyadenosine and 8-hydroxy-2'-deoxyadenosine are strongly resistant to acid-induced hydrolysis of the glycosidic bond. Mech. Ageing Dev. 2007, 128, 494-502. [CrossRef]

20. Das, R.S.; Samaraweera, M.; Morton, M.; Gascón, J.A.; Basu, A.K. Stability of N-glycosidic bond of (5'S)-8,5'-cyclo-2'-deoxyguanosine. Chem. Res. Toxicol. 2012, 25, 2451-2461. [CrossRef]

21. Mitra, D.; Luo, X.; Morgan, A.; Wang, J.; Hoang, M.P.; Lo, J.; Guerrero, C.R.; Lennerz, J.K.; Mihm, M.C.; Wargo, J.A.; et al. An ultraviolet-radiation-independent pathway to melanoma carcinogenesis in the red hair/fair skin background. Nature 2012, 491, 449-453. [CrossRef] [PubMed]

22. Wang, J.; Clauson, C.L.; Robbins, P.D.; Niedernhofer, L.J.; Wang, Y. The oxidative DNA lesions 8,5'cyclopurines accumulate with aging in a tissue-specific manner. Aging Cell 2012, 11, 714-716. [CrossRef] [PubMed]

23. Robinson, A.R.; Yousefzadeh, M.J.; Rozgaja, T.A.; Wang, J.; Li, X.; Tilstra, J.S.; Feldman, C.H.; Gregg, S.Q.; Johnson, C.H.; Skoda, E.M.; et al. Spontaneous DNA damage to the nuclear genome promotes senescence, redox imbalance and aging. Redox Biol. 2018, 17, 259-273. [CrossRef] [PubMed]

24. Mori, T.; Nakane, H.; Iwamoto, T.; Krokidis, M.G.; Chatgilialoglu, C.; Tanaka, K.; Kaidoh, T.; Hasegawa, M.; Sugiura, S. High levels of oxidatively generated DNA damage 8,5'-cyclo-2'-deoxyadenosine accumulate in the brain tissues of xeroderma pigmentosum group A gene knockout mice. DNA Repair 2019, 80, 52-58. [CrossRef] [PubMed]

25. Krokidis, M.G.; Louka, M.; Efthimiadou, E.K.; Zervou, S.-K.; Papadopoulos, K.; Hiskia, A.; Ferreri, C.; Chatgilialoglu, C. Membrane lipidome reorganization and accumulation of tissue DNA lesions in tumor-bearing mice: An exploratory study. Cancers 2019, 11, 480. [CrossRef] [PubMed]

26. Pande, P.; Das, R.S.; Shepard, C.; Kow, Y.W.; Basu, A.K. Repair efficiency of (5'S)-8,5-cyclo-2'-deoxyguanosine and (5'S)-8, 5' -cyclo-2'-deoxyadenosine depends on the complementary base. DNA Repair 2012, 11, 926-931. [CrossRef]

27. You, C.; Dai, X.; Yuan, B.; Wang, J.; Wang, J.; Brooks, P.J.; Niedernhofer, L.J.; Wang, Y. A quantitative assay for assessing the effects of DNA lesions on transcription. Nat. Chem. Biol. 2012, 8, 817-822. [CrossRef] 
28. Chatgilialoglu, C.; Guerra, M.; Mulazzani, Q.G. Model studies of DNA C5' radicals. Selective generation and reactivity of 2'-deoxyadenosin-5'-yl radical. J. Am. Chem. Soc. 2003, 125, 3839-3848. [CrossRef]

29. Chatgilialoglu, C.; Bazzanini, R.; Jimenez, L.B.; Miranda, M.A. (5'S)- and (5'R)-5',8-cyclo-2'-deoxyguanosine: Mechanistic insights on the 2'-deoxyguanosin-5'-yl radical cyclization. Chem. Res. Toxicol. 2007, 20, 1820-1824. [CrossRef]

30. Belmadoui, N.; Boussicault, F.; Guerra, M.; Ravanat, J.L.; Chatgilialoglu, C.; Cadet, J. Radiation-induced formation of purine $5^{\prime}, 8$-cyclonucleosides in isolated and cellular DNA: High stereospecificity and modulating effect of oxygen. Org. Biomol. Chem. 2010, 8, 3211-3219. [CrossRef]

31. Terzidis, M.A.; Ferreri, C.; Chatgilialoglu, C. Radiation-induced formation of purine lesions in single and double stranded DNA: Revised quantification. Front Chem. 2015, 3, 18-25. [CrossRef] [PubMed]

32. Valko, M.; Leibfritz, D.; Moncol, J.; Cronin, M.T.; Mazur, M.; Telser, J. Free radicals and antioxidants in normal physiological functions and human disease. Int. J. Biochem. Cell. Biol. 2007, 39, 44-84. [CrossRef] [PubMed]

33. Winterbourn, C.C. Biological Chemistry of rEactive Oxygen Species. In Encyclopedia of Radicals in Chemistry, Biology and Materials; Chatgilialoglu, C., Studer, A., Eds.; Wiley: Chichester, UK, 2012; Volume 3, pp. 1260-1281.

34. Geacintov, N.E.; Shafirovich, V. Reactions of Small Reactive Species with DNA. In Encyclopedia of Radicals in Chemistry, Biology and Materials; Chatgilialoglu, C., Studer, A., Eds.; Wiley: Chichester, UK, 2012; Volume 3, pp. 1284-1317.

35. Parlanti, E.; Pietraforte, D.; Iorio, E.; Visentin, S.; De Nuccio, C.; Zijno, A.; D’Errico, M.; Simonelli, V.; Sanchez, M.; Fattibene, P.; et al. An altered redox balance and increased genetic instability characterize primary fibroblasts derived from xeroderma pigmentosum group A patients. Mutat Res. 2015, 782, $34-43$. [CrossRef] [PubMed]

36. Ruggieri, F.; Alimonti, A.; Bocca, B. Full validation and accreditation of a method to support human biomonitoring studies for trace and ultra-trace elements. Trends Anal. Chem. 2016, 80, 471-485. [CrossRef]

37. Ferreri, C.; Chatgilialoglu, C. Role of fatty acid-based functional lipidomics in the development of molecular diagnostic tools. Expert Rev. Mol. Diagn. 2012, 7, 767-780. [CrossRef] [PubMed]

38. Terzidis, M.A.; Chatgilialoglu, C. An ameliorative protocol for the quantification of purine 5',8-cyclo-2'-deoxynucleosides in oxidized DNA. Front. Chem. 2015, 3, 47-56. [CrossRef] [PubMed]

39. Krokidis, M.G.; Terzidis, M.A.; Efthimiadou, E.; Zervou, S.K.; Kordas, G.; Papadopoulos, K.; Hiskia, A.; Kletsas, D.; Chatgilialoglu, C. Purine 5',8-cyclo-2'-deoxynucleoside lesions:formation by radical stress and repair in human breast epithelial cancer cells. Free Radic. Res. 2017, 51, 470-482. [CrossRef]

40. Chatgilialoglu, C. Cyclopurine (cPu) Lesions: What, How and Why? Free Radic. Res. 2019, 53, 941-943. [CrossRef]

41. Folch, J.; Lees, M.; Sloane Stanley, G.H. A simple method for the isolation and purification of total lipids from animal tissues. J. Biol. Chem. 1957, 226, 497-509.

42. Cort, A.; Ozben, T.; Melchiorre, M.; Chatgilialoglu, C.; Ferreri, C.; Sansone, A. Effects of bleomycin and antioxidants on the fatty acid profile of testicular cancer cell membranes. Biochim. Biophys. Acta - Biomembr. 2016, 1858, 434-441. [CrossRef]

43. Bocca, B.; Mattei, D.; Pino, A.; Alimonti, A. Uncertainty evaluation in the analysis of biological samples by sector field inductively coupled plasma mass spectrometry. Part A: Measurements of $\mathrm{Be}, \mathrm{Cd}, \mathrm{Hg}, \mathrm{Ir}, \mathrm{Pb}, \mathrm{Pd}$, $\mathrm{Pt}, \mathrm{Rh}, \mathrm{Sb}, \mathrm{U}, \mathrm{Tl}$ and $\mathrm{W}$ in human serum. Rapid Commun. Mass Spectrom. 2010, 24, 2363-2369. [CrossRef] [PubMed]

44. Bocca, B.; Mattei, D.; Pino, A.; Alimonti, A. Monitoring of environmental metals in human blood: The need for data validation. Curr Anal. Chem. 2011, 7, 269-276. [CrossRef]

45. Bocca, B.; Mattei, D.; Pino, A.; Alimonti, A. Uncertainty evaluation in the analysis of biological samples by sector field inductively coupled plasma mass spectrometry. Part B: Measurements of As, Co, Cr, Mn, Mo, Ni, Sn and V in human serum. Rapid Commun. Mass Spectrom. 2011, 25, 453-458. [CrossRef] [PubMed]

46. Lands, W.E. Metabolism of glycopeptides; a comparison of lecithin and triglyceride synthesis. J. Biol. Chem. 1958, 231, 883-888. [PubMed]

47. Prasinou, P.; Dafnis, I.; Giacometti, G.; Ferreri, C.; Chroni, A.; Chatgilialoglu, C. Fatty acid-based lipidomics and membrane remodeling induced by apoE3 and apoE4 in human neuroblastoma cells. Biochim Biophys Acta Biomembr. 2017, 1859, 1967-1973. [CrossRef] [PubMed]

48. Chatgilialoglu, C.; Ferreri, C.; Melchiorre, M.; Sansone, A.; Torreggiani, A. Lipid geometrical isomerism: From chemistry to biology and diagnostics. Chem. Rev. 2014, 114, 225-284. [CrossRef] [PubMed] 
49. Liochev, S.I.; Fridovich, I. The role of $\mathrm{O}_{2}$ in the production of HO: In vitro and in vivo. Free Radic. Biol. Med. 1994, 16, 29-33. [CrossRef]

50. Shanklin, J.; Guy, J.E.; Mishra, G.; Lindqvist, Y. Desaturases: Emerging models for understanding functional diversification of diiron-containing enzymes. J. Biol. Chem. 2009, 284, 18559-18563. [CrossRef]

51. Los, D.A.; Murata, N. Membrane fluidity and its roles in the perception of environmental signals. Biochim. Biophys. Acta. 2004, 1666, 142-157. [CrossRef]

52. Arbault, S.; Sojic, N.; Bruce, D.; Amatore, C.; Sarasin, A.; Vuillaume, M. Oxidative stress in cancer prone xeroderma pigmentosum fibroblasts. Real-time and single cell monitoring of superoxide and nitric oxide production with microelectrodes. Carcinogenesis 2004, 25, 509-515. [CrossRef]

53. Al- Ani, A.; Toms, D.; Kondro., D.; Thundathil, J.; Yu, Y.; Ungrin, M. Oxygenation in cell culture. Critical parameters for reproducibility are routinely not reported. PLoS ONE 2018, 13, e0204269. [CrossRef] [PubMed]

(C) 2019 by the authors. Licensee MDPI, Basel, Switzerland. This article is an open access article distributed under the terms and conditions of the Creative Commons Attribution (CC BY) license (http://creativecommons.org/licenses/by/4.0/). 